\title{
Análise da alteração no valor limite do IRI na qualidade funcional de pistas de pouso e decolagem de aeroportos brasileiros
}

\section{Analysis of the amendment in the limit value of the IRI in functional quality in landing and departure runway of Brazilian airports}

\section{Análisis del cambio en el valor limite del IRI en la calidad funcional en pistas de aterrizaje y despegue de aeropuertos brasileños}

Lucas Cavalcante de Almeida (OrclD) lucascavalcante@det. ufc.br

Universidade Federal do Ceará (UFC)

Francisco Heber Lacerda de Oliveira (OrcID)

heber@det.ufc.br Universidade Federal do Ceará (UFC)

José Wémenson Rabelo Chaves (OrclD) wemensonrabelo@gmail. com

Faculdade Cisne -

Quixadá-CE

\section{Analyse de la modification de la valeur limite de l'Indice International de Rugosité (IRI) sur la qualité fonctionnelle des chaussées aéronautiques brésiliennes}

\begin{abstract}
Resumo
A irregularidade longitudinal de pavimentos rodoviários e aeroportuários é caracterizada, no Brasil, pelo International Roughness Index (IRI -Índice de Irregularidade Internacional), um dos índices que permite a avaliação da serventia dos pavimentos. Considerando isso, este trabalho objetiva avaliar a irregularidade longitudinal nas pistas de pouso e decolagem dos aeroportos de João Pessoa, Recife, Salvador, Congonhas e Porto Alegre. Como resultado, devido à recente mudança no valor limite do IRI promovida pela Agência Nacional de Aviação Civil (ANAC), concluiu-se que a maioria das pistas de pouso e decolagem analisadas possuem valores de irregularidade longitudinal abaixo do nível considerado adequado.
\end{abstract}

Palavras-chave: Aeroportos. Pista de decolagem. Irregularidade longitudinal.

\begin{abstract}
The longitudinal irregularity of road and airport pavements, characterized in Brazil by the IRI (International Roughness Index), is one of the indices that allows the evaluation of the pavements usage. Considering this, the present work aims to evaluate the longitudinal irregularity in the landing and departure runways of João Pessoa, Recife, Salvador, Congonhas and Porto Alegre airports. As a result, due to the recent change in the IRI limit value promoted by the Agencia Nacional de Aviação Civil (ANAC), it was concluded that most of the landings and departures runways analyzed have values of longitudinal irregularity below the level considered adequate.
\end{abstract}

Keywords: Airports. Runway international. Roughness index.

\section{Resumed}

La irregularidad longitudinal de suelos de carreteras y de aeropuertos, caracterizados en Brasil por el IRI - International Roughness Index (Índice de Irregularidad Internacional), es uno de los índices que permite la evaluación de la utilidad de los suelos. Con esta consideración, este trabajo tiene el objetivo de evaluar la irregularidad longitudinal en los suelos de aterrizaje y despegue de los aeropuertos de João Pessoa, Recife, Salvador, Congonhas y Porto Alegre. Como resultado, debido al recién cambiado valor límite del IRI promovido por la Agencia 
Nacional de Aviación Civil (ANAC), se concluyó que la mayoría de las pistas de aterrizajes y despegues analizados poseen valores de irregularidad longitudinal con nivel por debajo de lo considerado adecuado.

Palabras-clave: Aeropuertos. Pista de despegue. Irregularidad longitudinal.

\begin{abstract}
Résumé
L'irrégularité longitudinale des chaussées routières et aéroportuaires, caractérisée au Brésil par I'IRI - International Roughness Index (Indice International de Rugosité), est l'un des indices qui permettent d'évaluer l'utilisation des chaussées. Dans cet esprit, cet article vise à évaluer l'irrégularité longitudinale des chaussées aéronautiques des aéroports de João Pessoa, Recife, Salvador, Congonhas et Porto Alegre. En raison de la modification récente de la valeur limite IRI faite par l'Agence Nationale de l'Aviation Civile Brésilienne (ANAC), il a été conclu que la plupart des chaussées aéronautiques analysées ont une valeur d'irrégularité longitudinale inférieure au niveau jugé adéquat.
\end{abstract}

Mots-clés: Aéroports. Chaussée aéronautique. Irrégularité longitudinale.

\title{
1 Introdução
}

De acordo com Bernucci et al. (2007), do ponto de vista do usuário, o estado da superfície do pavimento, ou, mais especificamente, do revestimento, é bastante relevante, pois as irregularidades nessa superfície são percebidas diretamente nos veículos, pelos usuários, afetando seu conforto ao rolamento.

Nos pavimentos aeroportuários essas irregularidades também afetam as aeronaves e seus componentes, acarretando maior custo operacional. Ao trafegarem sobre as irregularidades, a carga estática é acrescida devido aos efeitos dinâmicos que atuam, por um curto período de tempo, nas proximidades da irregularidade, provocando, assim, uma redução na serventia do pavimento.

Para a Federal Aviation Administration (FAA, 2009), o objetivo principal do sistema de suspensão de uma aeronave é absorver a energia desprendida durante a operação de pouso. Sistemas de suspensão de aeronaves têm menor capacidade para amortecer o impacto das irregularidades da superfície devido à magnitude da energia obtida durante as operações de pouso. A irregularidade do pavimento aeroportuário pode afetar o funcionamento seguro das aeronaves, ocasionando desde vibrações indesejáveis na cabine da aeronave a forças gravitacionais excessivas.

A infraestrutura aeroportuária tende, segundo Ramos (2014), à ocorrência de deterioração dos seus pavimentos, haja vista que está sujeita às operações de pouso e decolagem, além das intempéries da natureza, como a grande amplitude térmica diária, chuvas excessivas e nevadas. Por isso, os operadores de aeródromos devem priorizar as práticas de monitoramento e manutenção dos pavimentos para garantir o máximo de segurança aos usuários e tripulantes.

Do conjunto de indicadores que tratam da qualidade funcional e de segurança dos pavimentos, destaca-se a irregularidade longitudinal, comumente determinada pelo Internacional Roughness Index (IRI; em português, Índice de Irregularidade Internacional). Esse parâmetro, muitas vezes utilizado em pavimentos rodoviários, também é empregado no Brasil, em pistas de aeroportos, desde 2012, por requisição da Agência Nacional de Aviação Civil (ANAC, 2012), devido à facilidade de medição e disponibilidade de equipamentos, apesar de existirem estudos específicos que trazem métodos e descrevem equipamentos para esse tipo de medição (BARELLA, 2008).

No ano de 2018, por exigência da ANAC (2018), o valor do IRI foi alterado de 2,0 m/km para 2,5 m/km, para cada extensão de 200 metros. Desse modo, este trabalho possui como objetivo analisar as variações 
decorrentes dessa alteração dos valores limites de IRI nas pistas de pouso e decolagem de alguns aeroportos situados nas Regiões Nordeste, Sudeste e Sul do território brasileiro.

\section{Fundamentação Teórica}

Os pavimentos aeroportuários devem propiciar aos seus usuários um elevado nível de serviço, obedecendo a condições operacionais, de segurança e de qualidade necessárias, contribuindo de forma positiva com a segurança das operações de pouso e decolagem e mitigando possíveis ocorrências de acidentes e/ou incidentes de aeronaves (OLIVEIRA, 2009).

Para Fernandes (2010), os pavimentos aeroportuários são projetados, construídos e reabilitados para suportar as cargas impostas pelas aeronaves, bem como para proporcionarem uma condição confortável e segura. A qualidade integral do pavimento deve permitir que resista às condições climáticas, à ação do tráfego e às ações químicas provocadas pelos combustíveis, óleos e outros componentes poluentes presentes no pavimento. Nesse sentido, a FAA (2014) determina que os pavimentos aeroportuários devem se manter limpos e livres de partículas soltas que possam colocar em risco a segurança de movimentação das aeronaves.

Os pavimentos aeroportuários, segundo Ramos (2015), são estruturas projetadas e construídas para serem capazes de suportar as cargas impostas pelas aeronaves e, ao mesmo tempo, oferecer uma superfície confortável e segura para as operações de pouso e decolagem, tanto seca quanto molhada. Ainda conforme Ramos (2015), os pavimentos aeroportuários se distinguem dos rodoviários principalmente pela magnitude das cargas aplicadas, pelo menor número de repetições e, ainda, pela forma como o pavimento é solicitado, com esforços gerados pelo impacto no momento do pouso, o que não ocorre em rodovias.

Para Fernandes (2010), além das diferenças citadas por Ramos (2015), é possível incluir também a pressão e largura dos pneus, a configuração dos trens de pouso, o posicionamento do centro de gravidade da aeronave, a seção geométrica e a estrutura do pavimento. Outra característica marcante dos pavimentos dos aeródromos é o maior nível de exigência e controle, tanto na execução quanto na manutenção desses pavimentos, para a garantia de desempenho funcional da superfície, para que ofereça condições satisfatórias de aderência, a qual é aferida pelos parâmetros de coeficiente de atrito e macrotextura e de conforto ao rolamento, determinado pelo IRI (Índice de Irregularidade Internacional).

Segundo Fernandes (2010), aspectos como aderência pneu-pavimento (com especial importância para segurança das operações) ou irregularidade do pavimento (sobretudo importante do ponto de vista do conforto) revelam serem as maiores preocupações dos operadores aeroportuários. A irregularidade do pavimento, a medição do coeficiente de atrito e a textura superficial são os parâmetros que melhor qualificam esses aspectos.

\section{1 Índice de Irregularidade Internacional}

De acordo com DNER (1994), a irregularidade longitudinal de um pavimento é definida como o desvio da superfície da rodovia em relação a um plano de referência, que afeta a dinâmica dos veículos, a qualidade do rolamento e as cargas dinâmicas sobre a via. Existe um índice internacional para a medida da irregularidade, designado de IRI - International Roughness Index, que é um índice estatístico, expresso em m/km, concebido para pavimentos rodoviários, que quantifica os desvios da superfície do pavimento em relação à do projeto.

As primeiras recomendações para a definição e implementação de critérios básicos de irregularidade do pavimento, para pavimentos aeroportuários, foram propostas pela Federal Aviation Administration (FAA), no ano de 2009, com o objetivo de avaliar a superfície do pavimento em termos de aspereza e irregularidade, do pavimento e além do impacto que pode causar em aeronaves.

No Brasil, o IRI tem sido adotado em aeroportos desde dezembro de 2012, porém existem discussões em andamento, entre os operadores de aeródromos, sobretudo a Empresa Brasileira de Infraestrutura Aeroportuária (INFRAERO) e a ANAC, para se adotar outros métodos de avaliação de irregularidade longitudinal, que sejam mais adequados às pistas de pouso e decolagem (RAMOS, 2015). 


\section{2 Irregularidade Longitudinal - Pavimentos Aeroportuários}

Segundo a FAA (2009), a regularidade do pavimento é definida em termos da qualidade da superfície de rolamento experimentada pelo passageiro. Fabricantes de sistemas de suspensão automotiva buscam produzir equipamentos que reduzam o impacto das irregularidades da superfície, melhorando a qualidade do passeio.

Em contrapartida, o objetivo principal de um sistema de suspensão de uma aeronave é absorver a energia gasta durante o pouso. Sistemas de suspensão de aeronaves possuem menor capacidade de amortecer o impacto das irregularidades da superfície devido à magnitude da energia transferida durante o pouso.

O perfil de irregularidade é definido, ainda segundo FAA (2009), como desvios presentes sobre uma parte da pista, que causam reações nas aeronaves, de forma que podem aumentar a fadiga nos componentes, reduzir a capacidade de frenagem, prejudicar operações na cabine do piloto e/ou causar desconforto aos passageiros. Essas reações dependem do tamanho do avião, peso e velocidade. Mesmo quando a irregularidade longitudinal não causa desconforto aos usuários, essa irregularidade pode afetar a vida útil dos componentes das aeronaves ou diminuir a segurança operacional.

De acordo com Fernandes (2010), em relação à segurança nas operações em solo da aeronave, o efeito da carga dinâmica pode reduzir a capacidade de frenagem, pois a carga aplicada por eixo pode atingir duas ou mais vezes a carga estática. Esse conceito também acelera o ciclo de degradação do pavimento, além disso, provoca fadiga nos componentes das aeronaves, aumentando os seus custos de operacionais.

Outro fator que também afetam as operações da aeronave em solo devido às irregularidades é a capacidade do piloto em observar a instrumentação da cabine. Irregularidades da superfície podem causar vibrações na cabine da aeronave suficientes para que os pilotos percam a concentração ou tenham dificuldade para manipular os controles da aeronave durante o procedimento de pouso e decolagem (FAA, 2009).

Diante do exposto, os pavimentos aeroportuários são as infraestruturas mais exigentes em termos de IRI, sendo exigido valores iguais ou inferiores a $2,5 \mathrm{~m} / \mathrm{km}$ para cada extensão de 200 metros (ANAC, 2018). Até o ano de 2012, o valor de IRI estipulado era até $2 \mathrm{~m} / \mathrm{km}$.

O monitoramento da irregularidade longitudinal do pavimento deve ser feito por meio de medições, com equipamento que permita a obtenção de valores expressos no IRI. A Tabela 1 fornece os principais parâmetros que evidenciam as diferenças entre pavimentos aeroportuários e rodoviários.

Tabela 1 - Principais diferenças entre rodovias e aeródromos.

\begin{tabular}{|c|c|c|}
\hline Características & Rodovias & Aeródromos \\
\hline Largura das pistas & 7 a 10 metros & 20 a 50 metros (táxis: 10 a 25m) \\
\hline Comprimento & Vários quilômetros & Até cerca de 3000 metros \\
\hline Cargas & 10 tf por eixo, veículo 45 tf máximo. & $\begin{array}{l}100 \text { tf ou mais por trem de pouso principal, aviões } \\
\text { de até } 500 \text { tf. }\end{array}$ \\
\hline $\begin{array}{l}\text { Frequência de repe- } \\
\text { tição de cargas }\end{array}$ & $\begin{array}{l}\text { Por exemplo: } 2000 \text { veículos por dia, vários } \\
\text { milhões na vida de serviço, o efeito da fadiga } \\
\text { dos materiais é importante. }\end{array}$ & $\begin{array}{l}\text { Pequena, por dia: } 50 \text { a 100; menos de } 1.000 .000 \\
\text { na vida de serviço. }\end{array}$ \\
\hline $\begin{array}{l}\text { Pressão dos pneu- } \\
\text { máticos }\end{array}$ & 0,15 a $0,6 \mathrm{Mpa}\left(1,5 \mathrm{a} 6 \mathrm{kgf} / \mathrm{cm}^{2}\right)$ & 1 a 3 Mpa (10 a 30kgf/cm²) \\
\hline $\begin{array}{l}\text { Distribuição trans- } \\
\text { versal da carga nas } \\
\text { pistas }\end{array}$ & (Näo se faz diferenciaçäo transversal & $\begin{array}{c}\text { (diferencia-se o dimensionamento } \\
\text { transversalmente) }\end{array}$ \\
\hline
\end{tabular}


Tabela 1 - Principais diferenças entre rodovias e aeródromos. (continuação)

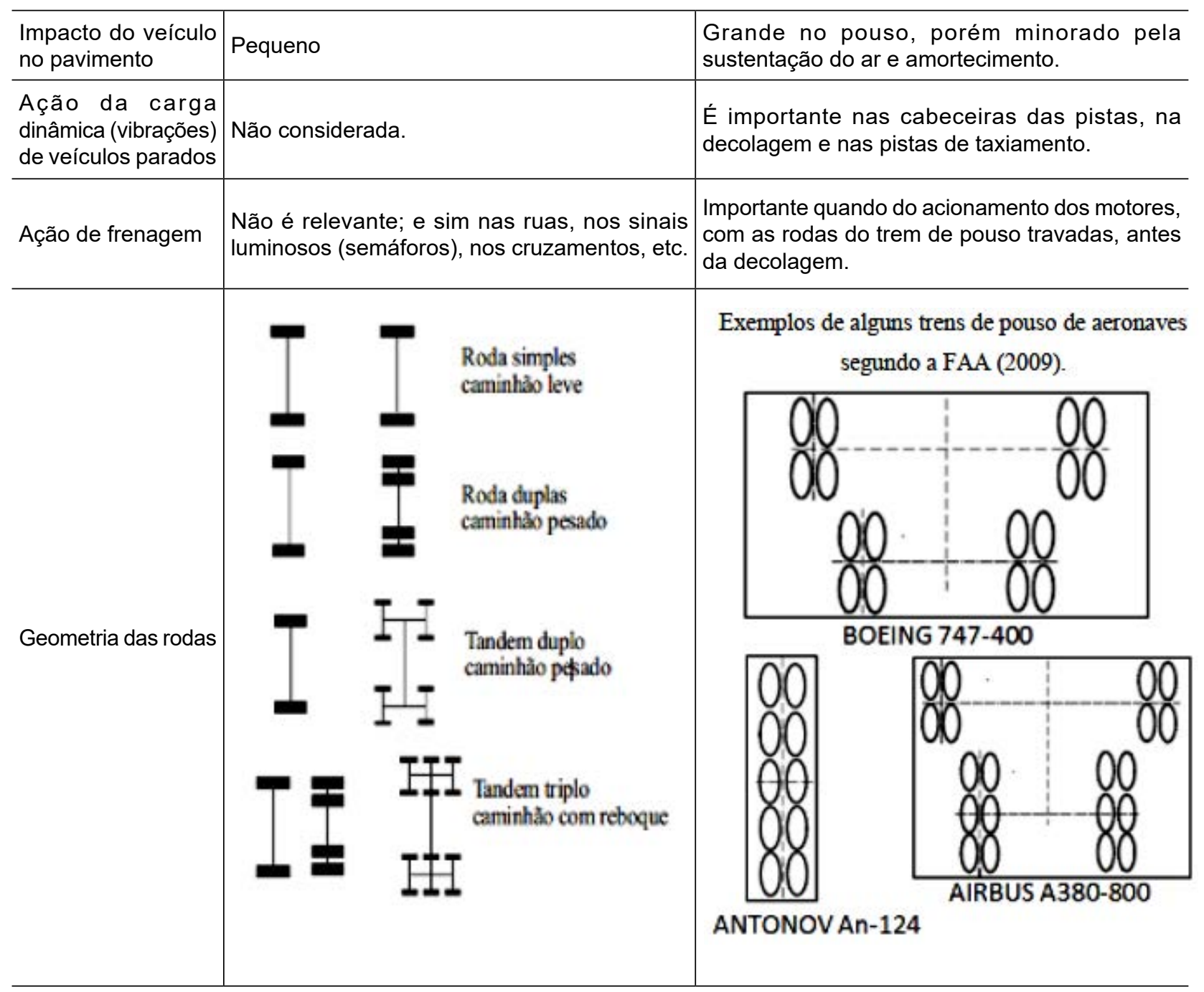

Fonte: Adaptado de Medina e Motta (2005).

A medição da irregularidade longitudinal do pavimento deve ser realizada ao longo de toda a extensão da pista de pouso e decolagem, a $3 \mathrm{~m}$ ou a $6 \mathrm{~m}$ do eixo, a depender da categoria do aeródromo, em ambos os lados, e deverá ser realizada após a construção ou recapeamento total de uma pista de pouso e decolagem, quando houver aumento na extensão longitudinal da pista e conforme periodicidade, a depender das características do aeroporto, tal como a quantidade de pousos diários (ANAC, 2018).

\section{Resultados e discussão}

Os dados dos índices de irregularidade internacional (IRI) foram obtidos através de ensaios de medição realizados em 7 (sete) pistas de pouso e decolagem, no ano de 2013, pelos operadores dos aeródromos de João Pessoa - Paraíba, Porto Alegre - Rio Grande do Sul, Recife - Pernambuco, Salvador-Bahia (duas pistas), e /Congonhas - São Paulo (duas pistas), em São Paulo. Os mencionados dados foram cedidos, por meio de relatórios técnicos de medição in situ, pela INFRAERO e pela ANAC, com uso do equipamento medidor de irregularidade longitudinal, denominado perfilômetro inercial a laser, conforme mostrado na Figura 1. Vale ressaltar que, conforme conhecimento dos autores, os operadores de aeródromos não efetuaram novas medições de IRI (no período entre 2013 a 2018), pois era aguardada a nova regulamentação por parte da ANAC. 
Figura 1 - Veículo e equipamento com perfilômetro inercial a laser.

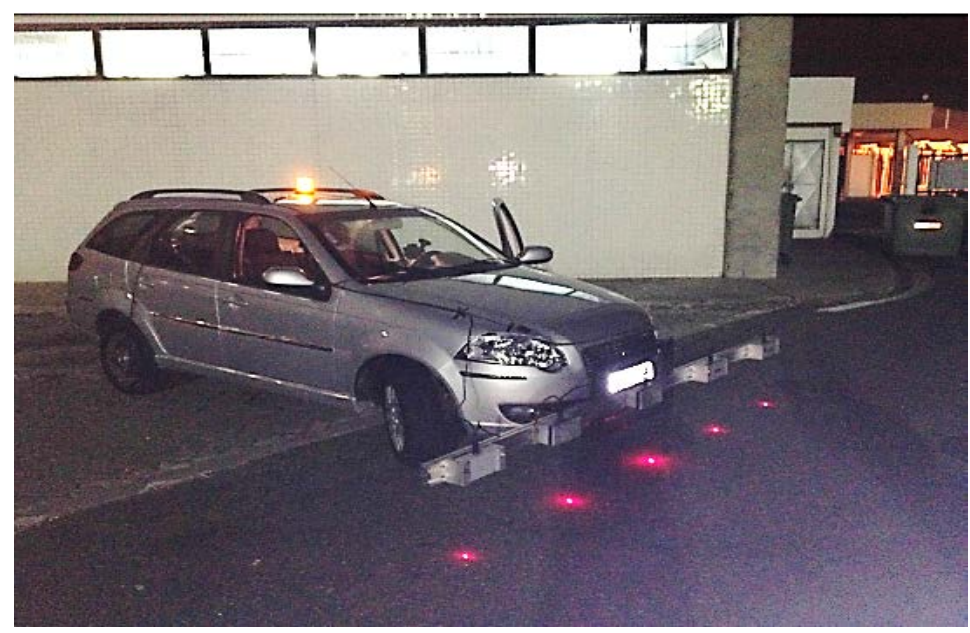

Fonte: Barella (2008)

Vale ressaltar que, para todas as pistas analisadas, o sentido da medição partiu da cabeceira de maior solicitação das operações, ou seja, o sentido no qual a aeronave parte para a decolagem. Para a análise dos dados foram elaborados gráficos de linhas a partir de tabelas e planilhas dos relatórios de obtenção dos dados anteriormente mensurados. A partir da análise dos gráficos foi possível comparar quantitativamente a alteração feita pela ANAC no valor de IRI. Por meio da análise dos gráficos apresentados nas Figuras 2 a 5 (Região Nordeste), ficou evidente a presença de irregularidades longitudinais bastante acentuadas em todas as pistas de pouso e decolagem, ultrapassando os limites de IRI impostos por ANAC (2012) na grande maioria das medições.

Em relação aos limites propostos por ANAC (2018), apenas o Aeroporto de João Pessoa apresentou a maioria dos valores de IRI abaixo do valor sugerido. Isto indica que, mesmo com a alteração no regulamento vigente, os perfis longitudinais das pistas de pouso e decolagem dos demais aeroportos da Região Nordeste analisados neste artigo estão em desacordo com os valores limites atuais. Deve-se atentar para a pista de pouso e decolagem do Aeroporto de Salvador, pista 35/17 (Figura 4), pois, mesmo após a modificação do regulamento, apresentou todos os valores de IRI acima do limite estabelecido.

Figura 2 - Aeroporto de João Pessoa.

\section{IRI - Aeroporto de João Pessoa}

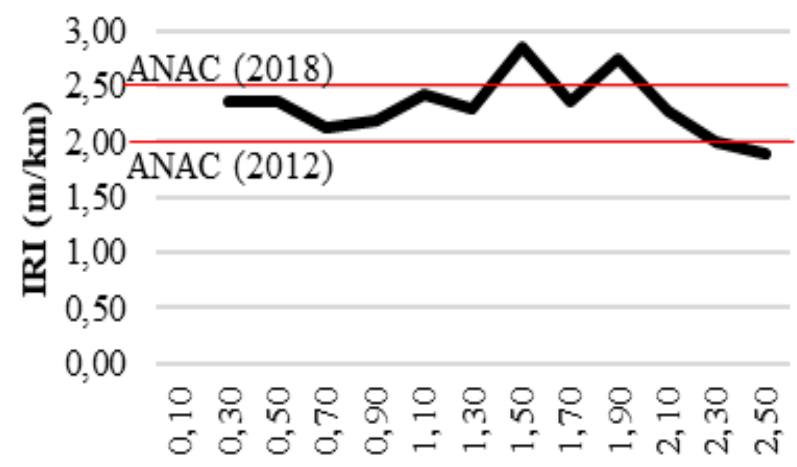

Extensão da pista $(\mathrm{km})$ 
Figura 3 - Aeroporto de Salvador (10/28).

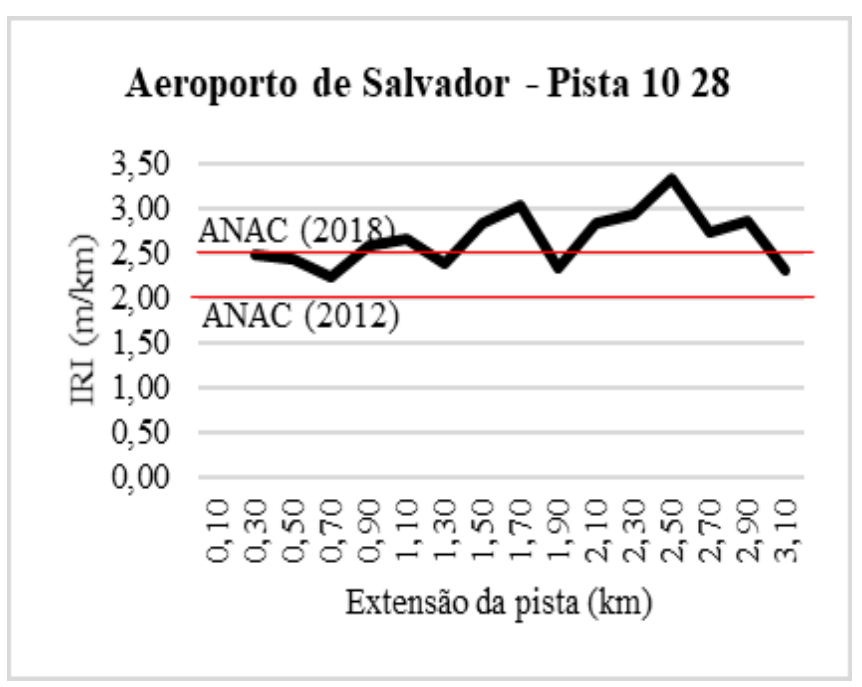

Figura 4 - Aeroporto de Salvador (35/17).

\section{Aeroporto de Salvador - Pista 3517}

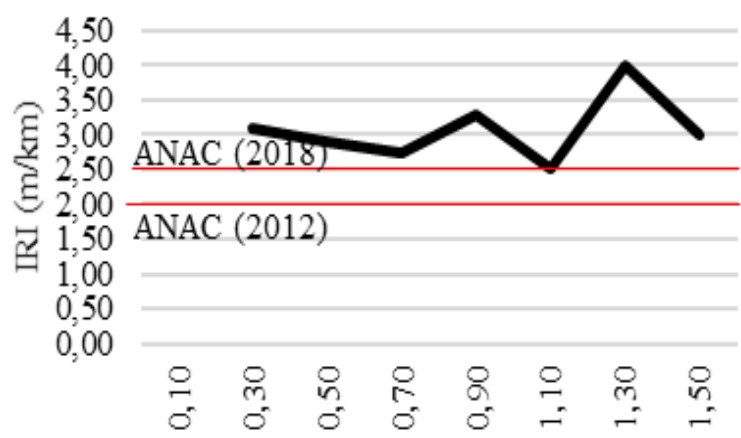

Extensão da pista (m)

Figura 5 - Aeroporto de Recife.

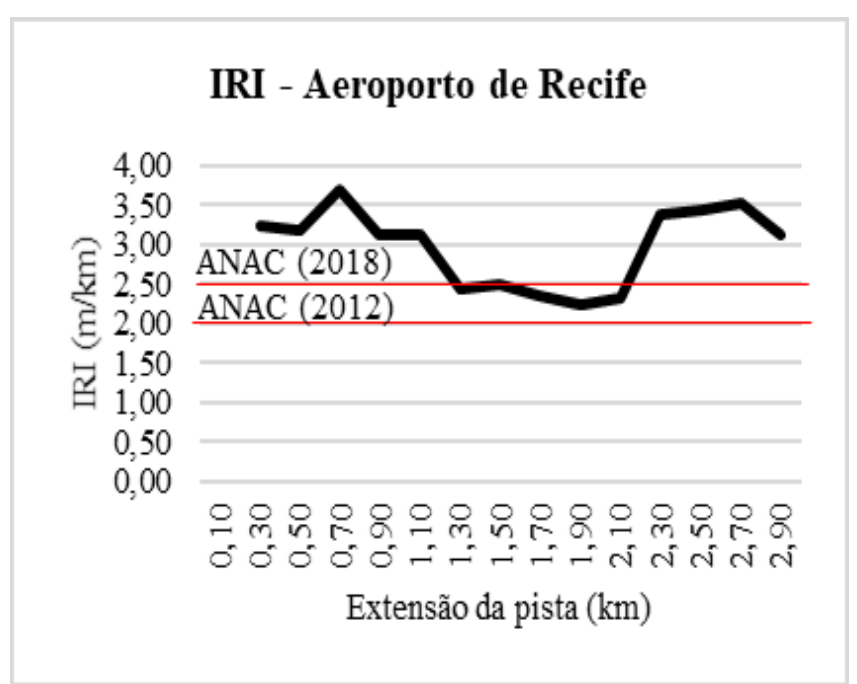


Nos demais aeroportos analisados, pertencentes às Regiões Sul e Sudeste do Brasil (Figuras 6 a 8), quanto à irregularidade longitudinal, pôde-se extrair que as pistas de pouso e decolagem apresentam uma homogeneidade nos resultados ao longo de sua extensão, refletindo um possível melhor controle executivo na construção das camadas do pavimento e seus respectivos materiais constituintes.

Figura 6 - Aeroporto de Porto Alegre.

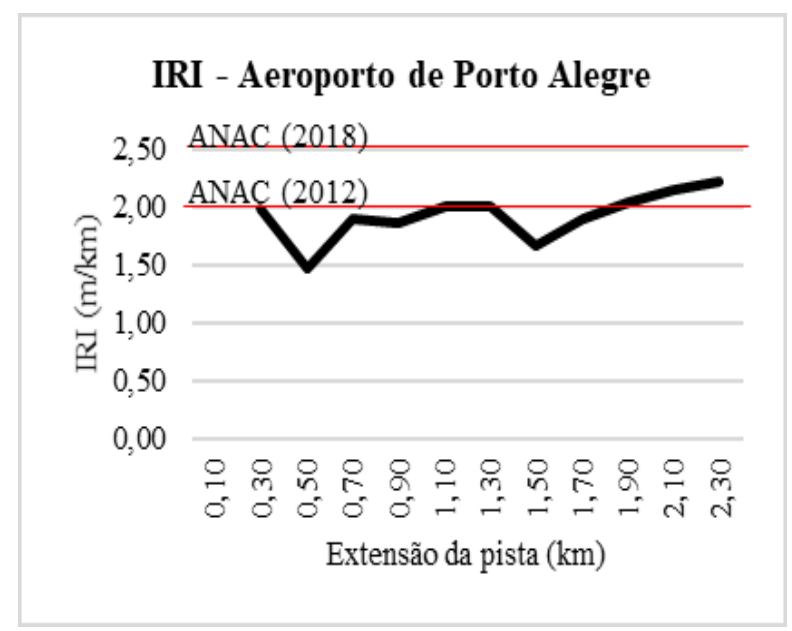

Figura 7 - Aeroporto de São Paulo (17L35R).

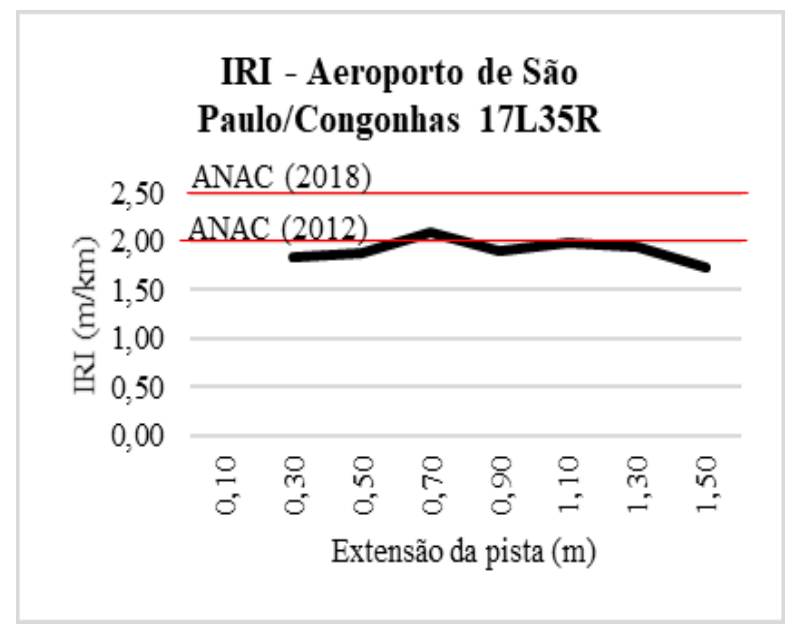

Figura 8 - Aeroporto de São Paulo (17R35L).

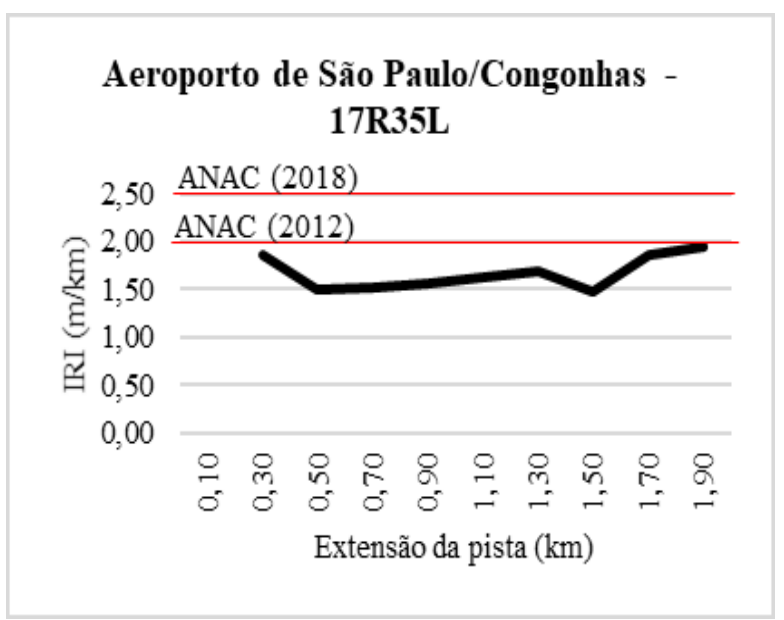


Por fim, através da análise dos gráficos apresentados ao longo dos estudos de caso, em algumas pistas, principalmente nas pistas da Região Nordeste, ficou claro a presença de irregularidades longitudinais bastante acentuadas. Nota-se que tal efeito é mais perceptível no revestimento nos trechos finais do $1^{\circ}$ terço e na extremidade da pista. Esses setores são os mais solicitados pelas aeronaves durante os pousos, são zonas sujeitas aos esforços que o pneu da aeronave aplica durante a aceleração para as decolagens, e são locais em que as aeronaves fazem o movimento para saída de pista, respectivamente.

\section{Conclusão}

A partir dos resultados obtidos nas medições da irregularidade longitudinal, tendo os resultados expressos em IRI - International Roughness Index, foi possível concluir que as pistas de pouso e decolagem dos aeroportos situados na Região Nordeste apresentaram, em sua grande maioria, os valores acima do limite estabelecido pela legislação vigente. Para o aeroporto de São Paulo/Congonhas, observou-se que poucos valores ficaram acima do recomendado. Na Região Sul, o aeroporto de Porto Alegre também apresentou alguns valores acima do normal para ambas as resoluções.

Em relação aos limites estabelecidos, foi possível constatar que o valor de IRI de $2 \mathrm{~m} / \mathrm{km}$, adotado até 2018, não possuía muita representatividade para os operadores de aeródromos, haja vista que a maioria das pistas analisadas ultrapassaram o limite exigido por ANAC (2012) e as operações de pouso e decolagem não foram suspensas, tampouco registraram ocorrências oriundas dessa natureza.

Com a alteração do IRI para $2,5 \mathrm{~m} / \mathrm{km}$, foram constatados que ainda existem índices situados acima desse limite em vários segmentos das pistas analisadas. Apesar da alteração no valor do parâmetro, fica evidente que o Índice de Irregularidade Internacional é representativo mesmo para pistas de pouso e decolagem, porém o valor estabelecido deve ser analisado com atenção, já que esse índice foi concebido para pavimentos rodoviários. Portanto, acredita-se que ANAC (2012) alterou o valor do IRI para adaptar o valor de pavimentos rodoviários para aeroportuários.

Através da análise dos gráficos apresentados ao longo dos estudos de caso, em algumas pistas, principalmente nas pistas da Região Nordeste, ficou clara a presença de irregularidades longitudinais bastante acentuadas em todas as pistas. Em alguns setores da pista, que são mais solicitados pelas aeronaves durante os pousos, essas zonas estão sujeitas aos esforços que o pneu da aeronave aplica durante a aceleração para as decolagens, o que pode contribuir para o acréscimo no valor da irregularidade longitudinal.

Nos demais aeroportos das Regiões Sudeste e Sul, quanto à irregularidade longitudinal, pôde-se extrair que as pistas de pouso e decolagem apresentam homogeneidade nos resultados ao longo de sua extensão, talvez refletindo um melhor controle executivo na construção das camadas do pavimento e seus respectivos materiais constituintes.

Pode-se atribuir, também, os elevados valores de IRI aos fatores como falhas construtivas, principalmente quanto aos critérios de acabamento da textura superficial de mistura asfáltica. $\mathrm{O}$ acréscimo da irregularidade longitudinal é causado, ainda, por defeitos que surgem no pavimento, que podem agravar-se devido à presença de trincas oriundas, principalmente, das intempéries (clima e temperatura) e das solicitações de cargas que também podem originar defeitos, como ondulações e corrugações, contribuindo para o aumento da irregularidade longitudinal.

A falta de uma análise presencial em cada uma das pistas abordadas no corrente trabalho foi uma das dificuldades encontradas para a realização deste estudo. Uma visita às pistas de pouso e decolagem dos aeroportos analisados facilitaria o diagnóstico da causa das irregularidades longitudinais através da relação com os defeitos apresentados nos pavimentos, tais como ondulações, remendos e outros.

De modo geral, a análise do IRI faz-se necessária para que se verifique a condição de conforto ao rolamento, principalmente para pistas rodoviárias. No entanto, para pistas aeroportuárias, esse conforto ao rolamento não é tão perceptível para o usuário, haja vista que o tempo de exposição do usuário às irregularidades é mínima. 
Apesar das irregularidades longitudinais presentes no pavimento aeroportuário não comprometerem efetivamente o conforto ao rolamento, comprometem a segurança das operações em solo e os componentes das aeronaves.

Para evitar esse desgaste precoce nos equipamentos das aeronaves é preciso que ocorram intervenções rotineiras. Isto reduziria a probabilidade de ocorrência de acidentes, bem como suas proporções. Para correção dessas irregularidades, a depender do nível de severidade, atividades de reabilitação, como recapeamento ou a remoção (fresagem), e execução de nova camada asfáltica (revestimento).

Além da análise do IRI, sugere-se, para trabalhos futuros, a análise do BBI (Boeing Bump Index) e RCl (Riding Comfort Index), parâmetros que analisam a irregularidade em países com os Estados Unidos e Canadá, respectivamente, e que foram desenvolvidos exclusivamente para pistas aeroportuárias, podendo analisar com maior precisão as irregularidades longitudinais em pavimentos aeroportuários, já que apenas essa alteração no valor limite do IRI, proposta por ANAC (2018), pouco alterou a condição funcional das pistas analisadas.

\section{Referências}

AGÊNCIA NACIONAL DE AVIAÇÃO CIVIL - ANAC. Relatório brasileiro de aviação civil n 153: Aeródromos - Operação, manutenção e resposta à emergência, 2012.

AGÊNCIA NACIONAL DE AVIAÇÃO CIVIL - ANAC. Relatório brasileiro de aviação civil $\mathbf{n}^{\circ}$ 153: emenda $n^{\circ}$ 02. Aeródromos - Operação, manutenção e resposta à emergência, 2018.

BARELLA, R. M. Contribuição para a avaliação da irregularidade longitudinal de pavimentos com perfilômetros inerciais. 2008. 369 f. Tese (Doutorado em Engenharia de Transportes) - Departamento de Engenharia de Transportes, Escola Politécnica da Universidade de São Paulo, São Paulo, 2008.

BERNUCCI, L. B. et al. Pavimentação Asfáltica. Formação básica para engenheiros. Petrobras. Rio de Janeiro: Abeda, 2007.

DEPARTAMENTO NACIONAL DE ESTRADAS DE RODAGEM - DNER. DNER-PRO 229/94. Calibração e controle de sistemas medidores de irregularidade de superfície de pavimento (Sistema Integradores IPR/USP e Maysmeter). Brasília 1994. Disponível em: < http://ipr.dnit.gov.br/normas-e-manuais/normas/ procedimento-pro/dner-pro229-94.pdf>. Acesso em: 22 set. 2018.

FEDERAL AVIATION ADMINISTRATION. United States Department of Transportation. Guidelines and procedures for measuring airfield pavement roughness. Advisory Circular - AC 150/5380-9. Washington: FAA, 2009.

FEDERAL AVIATION ADMINISTRATION. United States Department of Transportation. Guidelines and procedures for maintenance of airport pavements. Advisory Circular - AC 150/5380-6C. Washington: FAA, 2014

FERNANDES, C. I. C. S. H. Sistemas de gestão de pavimentos aeroportuários - caracterização e aplicabilidade. 2010. 189 f. Dissertação (Mestrado em Mestrados de Transportes) - Instituto Superior Técnico, Universidade Técnica de Lisboa, Lisboa, 2010.

MEDINA, J.; MOTTA, L. M. G. Mecânica dos pavimentos. 2. ed. Rio de Janeiro: UFRJ, 2005.

OLIVEIRA, F. H. L. Proposição de estratégias de manutenção de pavimentos aeroportuários

baseadas na macro textura e no atrito: estudo de caso do Aeroporto Internacional de Fortaleza. 2009. 178 f. Dissertação (Mestrado em Engenharia de Transportes) - Programa de Mestrado em Engenharia de Transportes, Universidade Federal do Ceará, Fortaleza, 2009. 
RAMOS, F. R. Q. Aplicação de SMA (Stone Matrix Asphalt) em pavimentos aeroportuários: estudo de caso do Aeroporto de Aracaju - SE. 2015. 174 f. Dissertação (Mestrado em Geotecnia), Escola de Minas, Núcleo de Geotecnia, Universidade Federal de Ouro Preto, MG, 174 pág, 2015.

RAMOS, S. P. Análises das condições de aderência dos pavimentos aeroportuários do Nordeste brasileiro. 2014. (Trabalho de Conclusão de Curso) - Universidade de Fortaleza, Fortaleza, 2014.

Sobre os autores

\section{Lucas Cavalcante de Almeida}

Mestre em Infraestruturas de Transportes - PETRAN pela Universidade Federal do Ceará - UFC (2018), graduado em Engenharia Civil pela Universidade de Fortaleza (2015) e em Engenharia de Teleinformática pela Universidade Federal do Ceará (2011).

\section{Francisco Heber Lacerda de Oliveira}

Doutor em Engenharia de Transportes pelo Programa de Pós-Graduação em Engenharia de Transportes da Universidade Federal do Ceará. Professor Adjunto do Departamento de Engenharia de Transportes da Universidade Federal do Ceará. Affiliate Member in the American Society of Civil Engineers - ASCE. Tem experiência em Planejamento do Transporte Aéreo, Operação, Manutenção e Reabilitação de Infraestruturas Aeroportuárias, especialmente em pavimentos de pátios e de pistas de pouso e decolagem.

\section{José Wémenson Rabelo Chaves}

Graduando em Engenharia Civil e monitor na disciplina de Geotécnica II pela Faculdade Cisne - Quixadá-Ceará.

Recebido em: 20.11 .2018

Aceito em: 15.04.2019 